\title{
Impact of Broken Family upon Adolescents' Behavior at Secondary Schools in AL- Najaf AL-Ashraf City
}

\author{
Mohammed Baqer Hassan', Khetam Mutashar Hatab² \\ ${ }^{1}$ Assistant Professor, Pediatric Department, Faculty of Nursing, University of Kufa, IRAQ, \\ ${ }^{2}$ Professor, Pediatric Department, Faculty of Nursing, University of Bagdad, IRAQ
}

\begin{abstract}
Background: Broken families It is the family under divorce, separation, death of father, death of mother and death of both parents. It is the legal termination of marriage. It is also the dissolution of marriage that is contracted between husband and wife by the judgment of a court of competent jurisdiction or by an act of the legislature. Separation and divorce have exclusion and negative effects on the behavior of children as well as the burden of education for those in charge of it, which involves risks to the psyche and the degree of coping with children.
\end{abstract}

Objectives: To determine broken families among secondary school adolescents, assess secondary school's adolescents' behaviors, determine the impact of broken families on adolescents' behaviors, and to findout the relationship between adolescent's behaviors underbroken family and their socio-demographic characteristics of age, gender, parent's education levels, family type and socio-economic status.

Methodology: Anon-probability (purposive) sample of (555) students, whose age are between 12 to 18 years have been selected; the sampling of study is divided into two stages which include: First stage: the school's selection by cluster, the AL-Najaf City divided to six districts, the schools selected randomly (36) school's boys and girls, from (130) total schools .Second stage: students under broken family selection by using the purposive sampling, while control group from each school students were randomly selected.

Results: Indicate that there is significant relationship between the adolescent's gender under broken family and their behavior domain excessive suffering, poor anger control and poor social conformity. While there is a non-significant relationship between the adolescent's gender under broken family and their other behavior domains. The results show that there is a highly significant relationship between adolescent's Educational level under broken family and their behavior domain poor impulse control and poor anger control. While there is a non-significant relationship between the adolescent's Educational level under broken family and their other behavior domains.

Conclusion: That most of the secondary school's adolescents under broken family have Behavior problems.

Recommendation: To the Governments and Schools should create awareness on the ills of broken homes on the academic, emotional and social adjustments of students through training, workshops and seminars. Parents should be enlightened on the need to stay together as husband and wife to raise a good family.

Keywords: Impact, Broken Family, Adolescents'Behavior, Secondary Schools.

\section{Corresponding Author:}

\section{Mohammed Baqer Hassan}

Assistant Professor, Pediatric Department, Faculty of

Nursing, University of Kufa, IRAQ,

e-mail: mohammedb.daghil@uokufa.edu.iq

\section{Introduction}

God created mankind and made the production of the offspring and its perpetuity of life through marriage between a man and a woman. Therefore, the family is considered the smallest social institution within the community, and the relationship that binds the father and 
the mother within the family, so the more coherent that relationship is, the stronger the society will be, because through the family, the first signs for raising a child and promoting values and good morals are launched ${ }^{(1)}$.

Family is the basic unit of society. A home is that where a family lives which provides children with feelings of security and stability. The members of family constitute the child's first environment for personal and social adjustment. Anything that interferes with these feelings can be regarded as hazardous for adolescents ${ }^{(2)}$.

The effects of a broken family on children depend on numerous factors, including child's age and personality when parents got separated, family relationships and the surrounding circumstances in which changes in the behavior of the child can occur from the simplest detail of the most complex, in addition to the child's ability to overcome these difficulties and favorable conditions ${ }^{(3)}$.

The impact of the broken family on children by shaping children's attitudes, feelings, thoughts, and behaviors, which are manifested by the increase in painful feelings of sadness, anxiety, confusion, fear, guilt, and the reinforcement of misconceptions and behaviors with the domination of some negative ideas that increase the suffering of children when there is an incoherent and disassembled family that has an impact On the quality of life of the adolescents in all areas ${ }^{(4)}$.

\section{Methodology}

Design of the Study: A descriptive study is conducted through the period of November $11^{\text {th }}, 2018$ to May $9^{\text {th }}, 2019$ in-order to Impact of Broken Family upon Adolescent's Behavior at Secondary Schools in AL- Najaf AL-Ashraf City.

Setting of the Study: The setting of the study includes (36) schools;(12) intermediate schools, (12) high schools (preparatory), and (12) secondary schools, which are distributed in six districts of Al-Najaf AlAshraf City, six schools from each quarter's.

\section{Results of the Study:}

Table (1): Distribution of the Study Sample by their Adolescents Demographic Data

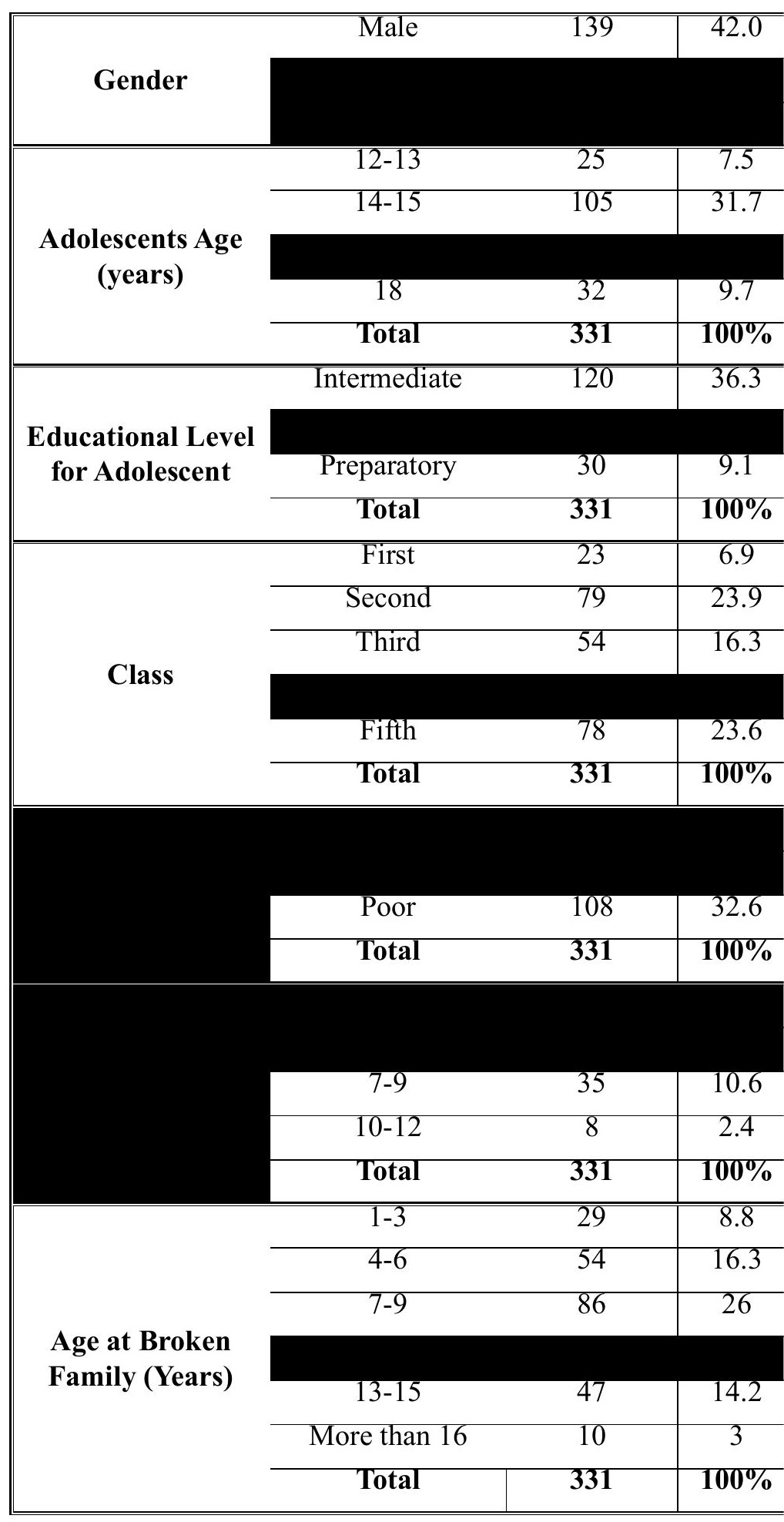

Table (1) indicates that more than half (51.1\%); (67\%) of ages are 16-17 years of broken and control samples respectively; while the results revealed that the highest percentage $(58 \%) ;(82.6 \%)$ is female of broken school

of broken and control samples respectively; more than quarter $(29.3 \%)$; $(45.1 \%)$ of broken and control samples 
respectively in fourth and fifth class, with average level (39.6\%) of broken sample, while good level $(89.7 \%)$ of education with control sample; the highest percentage of number children in the family is $(43.5 \%)$; $(46.4 \%)$ of four to six of both samples respectively; while age at broken family is more than third percentage (31.7\%) at ten to twelve years; the children rank in family is more than third percentage (37.1\%) at second in broken sample, while (44.2\%) at first in control sample.

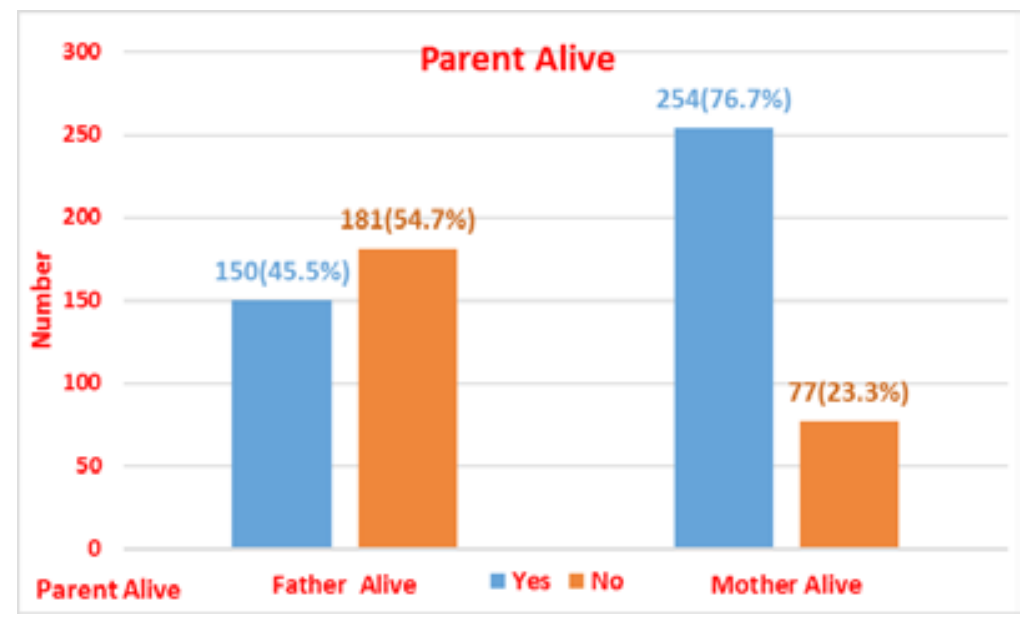

Figure (1): Distribution of the Study Sample by their Parent Alive

The findings in figure (1) indicate that the more than half percentage (54.7\%) of no father alive; while mother alive is two-third percentage (76.7\%)of broken family sample.

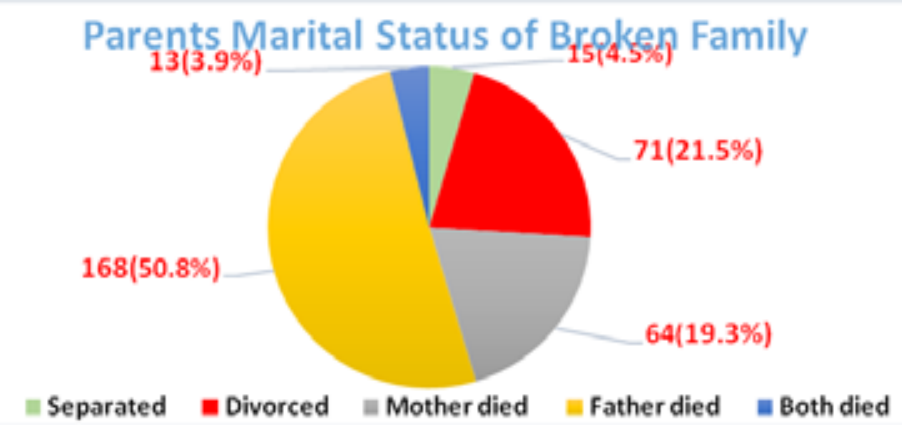

Figure (2): Distribution of the Study Sample by their Parents Marital Status

The findings in figure (2) indicates that the majority percentage $(50.8 \%)$ of father died and the divorced is $(21.5 \%)$; while lowest percentage $(3.9 \%)$ is both parent died of broken family.

Table (2): Association Between Educational Level for the Students and Adolescent's Behavior Levels of the Study Group

\begin{tabular}{|c|c|c|c|c|c|c|c|c|c|c|c|c|c|}
\hline \multirow{4}{*}{ Variables } & & \multicolumn{6}{|c|}{ Broken Family } & \multicolumn{6}{|c|}{ Control } \\
\hline & & \multicolumn{6}{|c|}{ Educational level for the students } & \multicolumn{6}{|c|}{ Educational level for the students } \\
\hline & & \multicolumn{2}{|c|}{ Good } & \multicolumn{2}{|c|}{ Average } & \multicolumn{2}{|c|}{ Poor } & \multicolumn{2}{|c|}{ Good } & \multicolumn{2}{|c|}{ Average } & \multicolumn{2}{|c|}{ Poor } \\
\hline & & No & $\%$ & No & $\%$ & No & $\%$ & No. & $\%$ & No. & $\%$ & No & $\%$ \\
\hline \multirow{4}{*}{$\begin{array}{l}\text { Burks } \\
\text { Behavior } \\
\text { Rating Scale } \\
\text { (BBRS) }\end{array}$} & Not (110-220) & 4 & 4.3 & - & - & 1 & 0.9 & 95 & 47.3 & 12 & 54.5 & - & - \\
\hline & Yes $(221-384)$ & 74 & 80.4 & 104 & 79.4 & 91 & 84.3 & 106 & 52.7 & 10 & 45.5 & 1 & 100 \\
\hline & Sign.(385- 550) & 14 & 15.2 & 27 & 20.6 & 16 & 14.8 & - & - & - & - & - & - \\
\hline & P. value & \multicolumn{6}{|c|}{0.007} & \multicolumn{6}{|c|}{0.655} \\
\hline
\end{tabular}

*Significant difference between proportions using P. Chi-square test at 0.05 level. 
Table (2) represent the association between the adolescent's behavior and their educational level for the students, the study results indicate that there is a significant association at p-value more than 0.05 ; at p-value (0.007) .

Table (3): Association Between Type of Family and Adolescent's Behavior Levels of the Study Group

\begin{tabular}{|c|c|c|c|c|c|c|c|c|c|}
\hline \multirow{4}{*}{\multicolumn{2}{|c|}{ Variables }} & \multicolumn{4}{|c|}{ Broken Family } & \multicolumn{4}{|c|}{ Control } \\
\hline & & \multicolumn{4}{|c|}{ Type of Family } & \multicolumn{4}{|c|}{ Type of Family } \\
\hline & & \multicolumn{2}{|c|}{ Nucleus } & \multicolumn{2}{|c|}{ Extended } & \multicolumn{2}{|c|}{ Nucleus } & \multicolumn{2}{|c|}{ Extended } \\
\hline & & No. & $\%$ & No. & $\%$ & No. & $\%$ & No. & $\%$ \\
\hline \multirow{4}{*}{$\begin{array}{l}\text { Burks Behavior } \\
\text { Rating Scale } \\
\text { (BBRS) }\end{array}$} & Not (110-220) & 3 & 1.7 & 2 & 1.3 & 94 & 46.8 & 13 & 56.5 \\
\hline & Yes (221-384) & 135 & 76.3 & 134 & 87.0 & 107 & 53.2 & 10 & 43.5 \\
\hline & Sign. (385-550) & 39 & 22.0 & 18 & 11.7 & - & - & - & - \\
\hline & P. value & \multicolumn{4}{|c|}{$0.041 *$} & \multicolumn{4}{|c|}{0.375} \\
\hline
\end{tabular}

*Significant difference between proportions using P. Chi-square test at 0.05 level.

Table (3) represent the association between the adolescent's behavior and their type of family, the study results indicate that there is a non-significant association at p-value more than 0.05; Burks behavior rating scale) at $\mathrm{p}$-value (0.041) .

Table (4): Association Between Socio Economic Status and Adolescent's Behavior Levels of the Study Group

\begin{tabular}{|c|c|c|c|c|c|c|c|c|c|c|c|c|c|}
\hline \multirow{4}{*}{ Variables } & & \multicolumn{6}{|c|}{ Broken Family } & \multicolumn{6}{|c|}{ Control } \\
\hline & & \multicolumn{6}{|c|}{ SE Status (income) } & \multicolumn{6}{|c|}{ SE Status (income) } \\
\hline & & \multicolumn{2}{|c|}{ Enough } & \multicolumn{2}{|c|}{ Little bit enough } & \multicolumn{2}{|c|}{ Not enough } & \multicolumn{2}{|c|}{ Enough } & \multicolumn{2}{|c|}{ Little bit enough } & \multicolumn{2}{|c|}{ Not enough } \\
\hline & & No. & $\%$ & No. & $\%$ & No. & $\%$ & No. & $\%$ & No. & $\%$ & No. & $\%$ \\
\hline \multirow{4}{*}{$\begin{array}{l}\text { Burks } \\
\text { Behavior } \\
\text { Rating Scale } \\
\text { (BBRS) }\end{array}$} & Not (110.220) & 3 & 2.2 & 2 & 1.7 & - & - & 85 & 50.0 & 22 & 40.7 & - & - \\
\hline & Yes (221.384) & 112 & 82.4 & 102 & 84.3 & 55 & 74.3 & 85 & 50.0 & 32 & 59.3 & - & - \\
\hline & Sign. (385.550) & 21 & 15.4 & 17 & 14.0 & 19 & 25.7 & - & - & - & - & - & - \\
\hline & P. value & \multicolumn{6}{|c|}{0.185} & \multicolumn{6}{|c|}{0.235} \\
\hline
\end{tabular}

*Significant difference between proportions using P. Chi-square test at 0.05 level.

Table (4) represent the association between the adolescent's behavior and their socio economic status, the study results indicate that there is a non -significant association at p-value more than 0.05; Burks Behavior Rating Scale (BBRS)at p-value (0.185) .

\section{Discussion of the Results}

Table (1) show distribution of the study sample by their adolescents demographic data, this table indicates that the highest percentage (more than half) $(58 \%)$; $(82.6 \%)$ are females of broken and control samples respectively. This result indicates that there were females students of broken homes more than males students in the secondary schools; these findings agree with results obtained from study done by) Pauwels and Svensson, (2017. This result is due to the presence of disputes between parents or family disintegration. This generates conflicts and problems for the children, as it leads the children, especially the girls, to research and clings to any outlet that leads them to alleviate or break out of these conflicts and to prove their existence, and this can only be found through school. Especially in the Najaf community, where the available resources for girls are much less than for boys with more supervision for girls, especially in adolescence, which is characterized by aspirations for freedom and independence ${ }^{(5)}$.

While the results revealed that more than half $(51.1 \%)$; $(67 \%)$ of age is $16-17$ years of broken and control samples respectively; these findings agree with results obtained from study done by (Tremblay et al., 2018). This result is due to the period in which they were born. The society has suffered in many political and 
economic problems, in addition to the openness that the country witnessed and other factors have rocked society, especially the family. The disintegration has increased during that period ${ }^{(6)}$.

Concerning the level of adolescent's education, the study indicates that more than half (54.7\%); (54.9\%) at secondary school of broken and control samples respectively; these findings agree with results obtained from study done by)Atsushiet al., 2018) ${ }^{(7)}$. While there are more than quarter $(29.3 \%) ;(45.1 \%)$ of broken and control samples respectively in fourth and fifth class, with average level (39.6\%) of broken sample, and good level $(89.7 \%)$ of education with control sample; these findings agree with results obtained from study done (Amato and Sobolewsk, 2001) ${ }^{(8)}$. This result is due to the fact that most of the samples members are between 16-17 years old and who are usually in this stage of study. Addition the lower educational level to middle due to loss or lack of supervision by the parents, with the mental, emotional and behavioral problems faced by the teenager, as well as difficulties in the family. All of this reflects negatively on all levels of the adolescent's life, especially the academic level, with the loss or lack of interest of the educational staff in the student, making the student's level be less than good.

The highest percentage of number children in the family are $(43.5 \%)$; $(46.4 \%)$ of fourth to sixth of both samples respectively; these findings agree with results obtained from study done by (Cohen, 2014). This result is due to the occurrence of most cases of family disintegration when the number of its members increases, which creates burdens on the family breadwinner and consequently the family's neglect and disintegration. Therefore, the order of adolescents plays a major role in determining the method of family upbringing, especially in dealing with children ${ }^{(9)}$.

While adolescent's age at broken family indicates that more than third $(31.7 \%)$ occurred at ten to twelve years; these findings agree with results obtained from study done by) Banket al., 2001). This result is due to the burdens of living and the increasing requirements of adolescents as they get older, with the inability of parents to manage family affairs with the problems of life facing the family in light of the unstable political, economic and security conditions of the country, with the increase in the number of family members. These factors can lead to family disintegration and incoherence ${ }^{(10)}$.
Children rank in family are more than third percentage $(37.1 \%)$ at second in broken sample, while $(44.2 \%)$ at first in control sample; while the results revealed that the highest percentage $(48.3 \%) ;(100 \%)$ is number of failure at less than one year of broken and control samples respectively; these findings agree with results obtained from study done by (Anderson et al., 2017). This result is due to the varied socio-demographic of the family who live in a poor or semi-poor family ${ }^{(11)}$.

Respondents were asked whether both parents were alive (Figure 1), the findings indicate that the more than half percentage $(54.7 \%)$ of no father alive; while mother alive is two-third percentage $(76.7 \%)$ of broken family sample; these findings agree with results obtained from study done by (Lauren and Laura, 2008). This result is due to the Iraqi society, especially Najafi, the main breadwinner for the family is the father, and the dependency is high, as well as the large role in meeting most of the basic needs necessary for family members, especially individuals without adolescence. In the case of losing the father, the entity and cohesion of the family can permeate or weaken and also generate economic and social burdens on the rest of the family members, especially the mother or big brother ${ }^{(12)}$.

Figure (2) show distribution of the study sample by their parents marital status, it indicates that the majority percentage $(50.8 \%)$ of father died and the divorced is $(21.5 \%)$; while lowest percentage $(3.9 \%)$ is both parent died of broken family; these findings agree with results obtained from study done by(Rialaet al., 2013). This result is due to living in single parent families or stepfamilies caused by death had higher negative consequences for adolescentthan living in single parent families caused by divorce, due to fathers take on the principal caring role. In general, the results of this study give support to the weak social position of the mother as the most likely explanation for the negative effects of living in a single parent family ${ }^{(13)}$.

Table (2) show association between educational level for the students related to the adolescent's behavior levels broken family in secondary schools, represent the association between the adolescent's behavior and their educational level for the students, the study results indicate that there is a significant association at $p$-value more than 0.05 ; these findings disagree with results obtained from study done by (Umar, 2019); the study results indicate that there is significant influence of broken homes on the academic adjustment of secondary school students ${ }^{(14)}$. 
Table (3) show association between type of family related to the adolescent's behavior levels broken family in secondary schools, represent the association between the adolescent's behavior and their type of family, the study results indicate that there is a non significant association at $p$-value more than 0.05 ; these findings agree with results obtained from study done by (Maggie, 2017);individual's adolescent family the study results indicate that the degree of support and sense of belonging individuals felt towards their family during adolescence, as well as their parent's relationship history were associated with low. Table (4) show association between socio economic status related to the adolescent's behavior levels broken family in secondary schools, represent the association between the adolescent's behavior and their socio economic status, the study results indicate that there is a non -significant association at $p$-value more than 0.05 ; these findings agree with results obtained from study done by (Hughes et al., 2017); the study results indicate that lower levels of family cohesion are an indicator of poor family relationships and may a healthy development. This result is due to the families characterized by unsupportive and neglectful relationships and conflict constitute risky environments that may lead to worse mental and physical health across the life, operating through pathways such as stress, emotion processing, social competence, and risky health behaviors ${ }^{(15)}$.

\section{Conclusions}

1. The study confirms that more than half of the study are female adolescent under broken family.

2. The study indicates that the broken family has a non-significant relationship to SESS.

3. The study indicates that most of adolescents have a behavior problems with their broken family.

4. The findings from this study lead to the conclusion that broken family have immense Impact of Adolescent's Behavior at Secondary Schools in ALNajaf AL-Ashraf City.

\section{Recommendations:}

1. Government should review upward minimum salary from the current amount to reasonable and substantial level to better the lives of the average citizen in the country.

2. Employment opportunities should be created for the unemployed parents.
3. Should, through enacting laws and the media, to enhance and improve the quality of family life.

3. Parents should be enlightened on the need to stay together as husband and wife to raise a good family. They should persevere and tolerate each other in marriage.

Financial Disclosure: There is no financial disclosure.

Conflict of Interest: None to declare.

Ethical Clearance: All experimental protocols were approved under the College of Nursing, University of Kufa, Iraq and all experiments were carried out in accordance with approved guidelines.

\section{References}

1. Wade T. J., Veldhuizen S., and Cairney J., Prevalence of Psychiatric Disorder in Lone Fathers and Mothers: Examining the Intersection of Gender and Family Structure on Mental Health, Canadian Journal of Psychiatry, 2016; 56(9), 567-573.

2. Langton C. E., and Berger L. M., Family Structure and Adolescent Physical Health Behavior and Emotional Well-Being, Social Service Review, 2015; 85(3): 323-357.

3. Wolchik S. A., Sandler I., Millsap R. E., Plummer B. A., Greene S. M., and Anderson E. R., Six Year Follow-up of a Randomized Controlled Trial of Preventive Interventions for Children of Divorce, Journal of the American Medical Association, 2012; 288: 1-8.

4. Pedro-Carroll J. L., Sutton S. E., and Wyman P. A., A Two Year Follow-up Evaluation of a Preventive Intervention for Young Children of Divorce, School Psychology Review, 2015; 28: 467-476.

5. Pauwels L, Svensson R. Analyzing Gender Differences in the Relationship between Family Influences and Adolescent Offending among Boys and Girls. European Journal of Criminology. 2017; 10(4): 1079-1094.

6. Tremblay RE, Pagani-Kurtz L, Mâsse LC, Vitaro F, Pihl RO. Individual family and school level interventions targeting multiple risk behaviours in young people. Journal of Consulting and Clinical Psychology. 2018;63(4):560-8.

7. Amato PR, Sobolewski JM. The effects of divorce and marital discord on adult children's 
psychological well-being. American Sociological Review. 2001;66:900-921.

8. Cohen GJ, The impact of family structure on the health of children: Effects of divorce. London: University of London, Institute of Education, Thomas Coram Research Unit. 2014 Nov; 110(5):1019-23.

9. Bank L, Marlowe JH, Reid JB, Patterson GR, Weinrott MR. Family and parenting interventions in children and adolescents with conduct disorder and delinquency aged 10-11 Journal of Abnormal Child Psychology Published online $2001: 23$.

10. Anderson NJ, Neuwirth SJ, Lenardson JD, Hartley D.; 2017.Differences in Health Care, Family, and Community Factors Associated with Mental, Behavioral, and Developmental Disorders Among Children Aged 2-8 Years in Rural and Urban Areas. 2017; (17). 10: 155 .

11. Lauren E. Glaze and Laura M. Maruschak,Parents in Prison and Their Minor Children, Department of Justice Office (2008) .Amercain Joruna 8(3): 4146.
12. Riala, K., Isohanni, I., Jokelainen, J, Jones, P. and Isohanni, M. 'The relationship between childhood family background and educational performance, with special reference to single-parent families: a longitudinal study', Social Psychology of Education, (2013); 6(4), pp. 349-365.

13. Umar Usman Sani, Influence of Broken Homes on Senior Secondary School Students' Academic, Emotional and Social Adjustments in Katsina State, Nigeria. International Journal of Innovative Psychology \& Social Development. 2019; 7(1):2632.

14. Maggie L. Thorse . The Adolescent Family Environment and Cohabitation across the Transition to Adulthood . Department of Sociology \& Anthropology, Montana State University. 2017;75(5):249-262.

15. Hughes K., Bellis M.A., Hardcastle K.A., Sethi D., Butchart A., Mikton C., Jones L., Dunne M.P. Poor Family Relationships in Adolescence and the Risk of Premature Death: Findings from the Stockholm Birth Cohort Study. Lancet Public Health. 2017;2:e356-e366. doi: 10.1016/S24682667(17)30118-4. 